\title{
Evaluación de sustratos orgánicos para la aclimatación y endurecimiento de vitroplantas de yuca (Manihot esculenta Crantz)
}

\section{Evaluation of organic substrates for acclimatization and hardening of vitroplants of cassava (Manihot esculenta Crantz)}

\author{
Avaliação de substratos orgânicos para aclimatação \\ e endurecimento das mudas \\ de mandioca (Manihot esculenta Crantz)
}

\author{
Miguel Macgayver Bonilla Morales ${ }^{1}$, Sergio Adolfo Sánchez Ordoñez \& \\ Jorge Pachón García ${ }^{3}$ \\ 'Licenciado en Producción Agropecuaria, Magister en Ciencias Biológicas con énfasis en Recursos \\ Fitogenéticos Neotropicales. '2icenciado en Producción Agropecuaria. 3Biólogo, Especialista en \\ Recursos Fitogenéticos. Magister en Ciencias Biológicas, Estudiante de Doctorado en Ciencias \\ Agrarias de la Universidad de los Llanos. Villavicencio. Meta. Colombia \\ 'Departamento de Ciencias Biológicas. Facultad de Ciencias Agropecuarias. Universidad Nacional \\ de Colombia Sede Palmira. Palmira. Colombia. ${ }^{2}$ Unidad Educativa trietnica YAALIAKEISY. Puerto \\ Gaitán. Meta. Colombia. 3Departamento de Ciencias Básicas, Facultad de Ciencias Básicas e \\ Ingenierías. Universidad de los Llanos. Villavicencio. Meta. Colombia \\ 1mmbonillam@unal.edu.co, ${ }^{2}$ sergio-Ipa@hotmail.com, \\ 3jotapachon@hotmail.com
}

\section{Resumen}

La adaptación de las vitroplantas a condiciones fisiológicas ambientales (endurecimiento) es uno de los puntos más críticos del proceso de obtención de plantas a través del cultivo de tejidos. De tal manera, el cuello de botella de la producción de material es la etapa ex vitro, aun en yuca donde se han reportado cifras que alcanzan el $90 \%$ de pérdidas. Por tal motivo, el objetivo fue definir sustratos orgánicos que permitirán la aclimatación y crecimiento de vitroplantas de yuca (Manihot esculenta) variedad brasilera. Por esta razón, se evaluaron tres tipos de sustratos orgánicos: MB 1 (humus sólido + cascarilla de arroz seca 1:1), MB2 (humus sólido + viruta 1:1) y MB
(Bocashi) para el endurecimiento de plantas con 8 semanas in vitro. El sustrato MB1 permitió la sobrevivencia y adaptación del $80 \%$ de las vitroplantas, en comparación con el MB2 32,5\% y el MB sin ninguna. El tiempo de duración de la etapa ex vitro fue hasta 60 días y su relación con el número de nudos (12), hojas (8) y a la altura de las plantas $(31 \mathrm{~cm})$ es el más representativo para el MB1. En conclusión, el sustrato MB1 es considerado el idóneo, tanto a nivel nutricional como componente estructural del suelo al tener una porosidad adecuada para el enraizamiento de la planta y permitir una mejor adaptación en fase de campo. 
Palabras clave: cultivo de tejidos, ex vitro, in vitro, recurso fitogenético.

\section{Abstract}

The adaptation of vitroplants at physiological environmental conditions (hardening) is one of the most critical points in the process of obtaining plants through tissue culture. Thus, the bottleneck of the material production is the ex vitro stage, even for cassava production, where the figures reported reached $90 \%$ of loss. The objective of this study was to define organic substrates that allowed acclimatization and growth of cassava plantlets (Manihot esculenta) Brazilian variety. MB 1 (solid humus + husk dry rice 1:1), MB2 (solid humus + shaving 1: 1) and MB (Bocashi) for hardening of 8 weeks in vitroplants. The substrate MB1 allowed the survival and adaptation of $80 \%$ of the vitroplants, compared with $32.5 \%$ and $0 \%$ for MB2 and MB respectively. The duration of $e x$ vitro stage was up to 60 days ; in the case of MB1, its relation to the number of nodes (12), leaves (8) and plant height $(31 \mathrm{~cm})$ is the most representative. In conclusion, the MB1 substrate is considered suitable both nutritional level and structural component of the soil for having an adequate porosity for rooting of plant and an ideal adaptation field phase.

Key-words: in vitro, plant genetic resource, tissue culture.

\section{Resumo}

A adapatação de vitroplantas a condições fisiológicas ambientais (endurecimento) é um dos pontos mais críticos do procceso de obtenção de plantas através da cultura de tecidos. Nesse sentido, o gargalho da produção de material é a etapa ex vitro, mesmo em mandioca onde tem-se reportado dados que atingem $90 \%$ de perdas. Por tal motivo, o objetivo desse trabalho foi definir substratos orgânicos que permitirão a aclimatação e crescimento de vitroplantas de mandioca (Manihot esculenta) variedades brasileira. Três tipos de substratos foram avaliados: MB1 (humus sólido + casca de arroz seca 1:1), MB2 (humus sólido + viruta 1:1) y MB (Bocashi) para o endurecimento de plantas com oito semanas in vitro. $\mathrm{O}$ substrato MB1 possibilitou a supervivência y adaptação de $80 \%$ das viroplantas em relação com MB2 (32.5\%) e MB sem nenhuma. O período de tempo da etapa ex vitro foi até de 60 dias e a sua relação com o número de nodos (12), folhas (8) e altura das plantas $(31 \mathrm{~cm})$ foi o mais representativo para o tratamento MB1. Como conclusão, o substrato MB1 é considerado ideal quanto a nível nutricional como componente esrtructural do solo por ter uma porosidade adequada para o enraizamento da planta e permitir uma adequanda adaptação em fase de campo.

Palavras-chave: cultura de tecidos, ex vitro, in vitro, recursos genéticos de plantas

\section{Introducción}

Tradicionalmente, la yuca ha sido una fuente de carbohidratos para sectores de la población con bajos niveles de ingresos a nivel mundial, por lo que su cultivo es considerado uno de los recursos fitogenéticos más importantes en la seguridad alimentaria (Bonilla, Pachón \& Moreno, 2015). En cuanto a los componentes agronómicos de raíces y tubérculos en Latinoamérica, dentro de las bondades del cultivo de la yuca, se resaltan su alto rendimiento en condiciones del trópico, como son los bajos niveles de fertilidad y acidez en el suelo (Suárez \& Mederos, 2011).
La yuca presenta otros usos, dentro de estos, su follaje que ha sido utilizado como fuente de proteína para la producción animal en sistemas agroforestales (Preston et al., 1987; Souza et al., 2006). Actualmente, este cultivo ha tomado una nueva dimensión debido a sus altos potenciales de rendimiento y sus nuevos usos industriales, especialmente, para la producción de biocombustible, por lo que se ha producido un incremento en las áreas de cultivo con fines de generar combustibles alternativos (Cortés, Chavarriaga \& López, 2010). 
Durante, el proceso de cultivo de tejidos vegetales en yuca, la etapa ex vitro resulta ser una limitante para finalizar la aclimatación y su posterior salida a campo (Segovia et al., 2002; Laynez \& Sánchez 2006; Marín, Albarrán, Fuenmayor \& Perdomo 2009). Inicialmente, las plantas deben ajustar su fisiología estomática a las condiciones de evapotranspiración imperantes y activar la toma de agua y nutrientes a través del sistema radicular (Bonilla, Mancipe \& Aguirre, 2015). Los sustratos utilizados en el proceso de endurecimiento son variados y todos coinciden en permitir un buen drenaje del suelo de manera que se mantengan los niveles de humedad requeridos y se evite la contaminación con patógenos (Bonilla, Sánchez \& Pachón, 2015).

La etapa ex vitro exige que en el invernadero se controle la humedad, temperatura, luminosidad, un sustrato aséptico y una debida nutrición para la aclimatación (Bonilla \& Hernández, 2012). Por eso, al no aplicar la tecnología idónea para la etapa de endurecimiento, se pueden alcanzar pérdidas entre 50 y 95\% (Segovia et al., 2002). En este orden lógico, los costos de manejo ex vitro versus la pérdida de vitroplantas resultan ser altos, lo cual sumado con los procesos a nivel de introducción y procesamiento del material vegetal in vitro, no sería una alternativa rentable de producción masiva de plantas. Por tal razón, el objetivo de esta investigación fue evaluar sustratos orgánicos de fácil acceso y preparación que permitan mejorar los procesos de adaptación de vitroplantas de yuca variedad brasilera (cultivada en el departamento del Meta, Colombia) y disminuir las pérdidas inherentes a su manejo, así como reducir los costos de la etapa ex vitro con la finalidad de hacer más rentable la producción.

\section{Materiales y métodos}

\section{Sitio de estudio}

En el invernadero del Laboratorio de Biotecnología Vegetal y Mejoramiento Genética, adscrito a la Facultad de Ciencias Agropecuarias y Recursos Naturales, Universidad de los Llanos, sede Barcelona vía Puerto López (departamento del Meta, Colombia), a una altitud de $422 \mathrm{msnm}$ y temperatura ambiental promedio de $25^{\circ} \mathrm{C}$.

\section{Material vegetal}

Se seleccionaron vitroplantas de yuca (Manihot esculenta) variedad brasilera de octavo subcultivo y con ocho semanas de desarrollo que crecían en frascos de vidrio que contenían $20 \mathrm{ml}$ de medio de cultivo preparado con sales inorgánicas de Murashige \& Skoog (1962), 0,5 mg L-1 de tiamina-HCL, $100 \mathrm{mg} \mathrm{L}^{-1}, 100 \mathrm{mg} \mathrm{L}^{-1}$ de myo-inositol, $30 \mathrm{~g} \mathrm{~L}^{-1} \mathrm{de}$ sacarosa, 2,3 $\mathrm{g} \mathrm{L}^{-1}$ de agar (Phytagel) y $\mathrm{pH}$ ajustado de 5.8. Las condiciones de laboratorio fueron: temperatura de $30^{\circ} \mathrm{C}$, intensidad lumínica de 3000 Lux y con un fotoperíodo de 16 horas luz y 8 de noche.

\section{Preparación de sustratos orgánicos}

Siguiendo directrices de Escobar (2013) para la obtención de humus sólido, se cultivaron lombrices rojas californianas (Eisenia fétida Savigny) en canastas, en la granja de la Universidad de los Llanos (Meta, Colombia) que se alimentaron con estiércol (bovino) fresco. A los dos meses y medio se tomó el humus sólido y se realizaron dos tipos de sustratos: MB 1 humus sólido + cascarilla de arroz seca (1:1) y MB2 humus sólido + viruta (1:1). Además, se preparó un tercer sustrato MB: Bocashi bajo el mismo tiempo mediante lo estipulado por la FAO (2011). Después los sustratos fueron llevados a la autoclave a $121^{\circ} \mathrm{C}$ durante 20 minutos para esterilización.

\section{Diseño experimental}

Las plantas fueron colocadas en macetas de 8 $\mathrm{cm}$ de diámetro, las cuales fueron llenadas con cada uno de los sustratos: MB1 y MB2, y MB que corresponde al control negativo, pues es un sustrato que netamente está constituido por compuestos orgánicos y sin un componente extra que le permita tener porosidad, por lo que las plantas no podrán endurecerse y aclimatarse. La unidad experimental fue de 10 vitroplantas y se realizaron tres réplicas para cada uno, para un total de 40 plantas por tratamiento. La aclimatación se hizo manteniendo cámara humedad y retirada progresivamente de acuerdo con el desarrollo vegetativo. Las variables a tener en cuenta para el endurecimiento fue \% sobrevivencia (adaptación), número de nudos, hojas presentes y altura al final de la etapa de endurecimiento. 


\section{Análisis}

Los datos de sobrevivencia se tuvieron en cuenta según si la planta quedaba viva (si) o muerta (no) al final del proceso. Se aplicaron pruebas de estadística descriptiva con el programa SPSS versión 20 , generando gráficos de medias para número de nudos, hojas presentes y altura al final de la etapa de endurecimiento.

\section{Resultados y discusión}

El sustrato MB1 permitió la sobrevivencia y adaptación del $80 \%$ de las vitroplantas, en comparación con el sustrato MB2 de un $32,5 \%$ y el sustrato MB sin ninguna (Figura 1). Generalmente, las pérdidas de material vegetal en cultivo de tejidos, van desde la etapa in vitro con un medio artificial y condiciones de laboratorio controladas, a la etapa ex vitro donde se transfiere a un suelo y bajo condiciones que no se pueden controlar totalmente, por lo que no regular los factores edafoclimáticos, puede generar hasta un 90\% de pérdidas del material (Segovia et al., 2002).

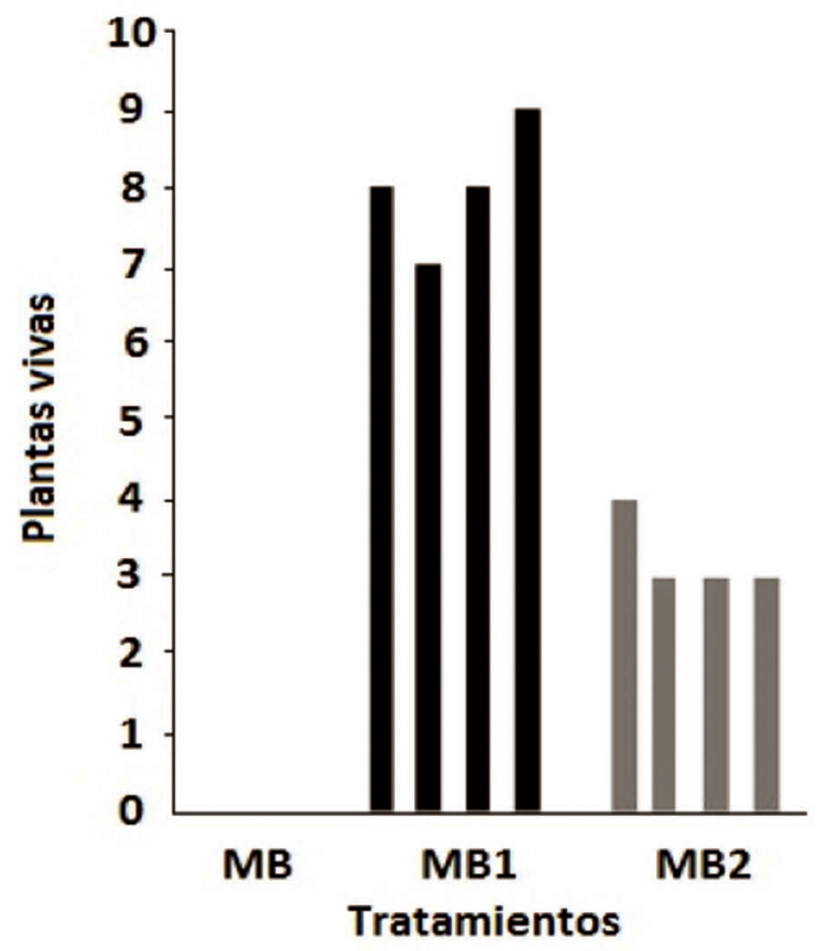

Figura 1. Sobrevivencia de plantas de yuca (M. esculenta) de acuerdo a los tratamientos MB, MB1 y MB2 con sus respectivas replicas.
Además, factores como la luz y la temperatura que se manejen a nivel in vitro pueden incidir en la aclimatación, donde la intensidad lumínica es uno de los principales factores que influye (Jorge et al., 2001). Sin embargo, en este caso esos factores no presentaron diferencia en la sobrevivencia, pues en algunos grupos del tratamiento MB1 se alcanzó el $90 \%$ de plantas vivas. Adicionalmente, conforme a lo planteado por Bonilla, Sánchez \& Pachón (2015), se hace un proceso de pre-aclimatación entre la fase in vitro y ex vitro, para que las plantas no sufran tanto los cambios climáticos.

Las plantas tratadas con el sustrato MB1 presentaron mayor desarrollo que llega hasta 12 nudos y 8 hojas, a diferencia del MB2 que presenta 10 nudos y 6 hojas (Figura 2). Durante la fase de laboratorio e invernadero, los factores que están relacionados en el desarrollo de nudos y hojas son la intensidad lumínica e incidiendo más la temperatura (Jorge et al., 2001). De tal manera, en las plantas de yuca tanto en la fase in vitro como ex vitro, se manejó la misma temperatura, y en cuanto a la luminosidad, se realizó una transición idónea controlada desde la cámara húmeda. Aun así, esta relación es muy importante y debe tenerse en cuenta, ya que cuando se manejan efectos de salinidad en yuca en la etapa in vitro se ven reflejados en la etapa ex vitro (Carretero, Cantos, García \& Troncoso, 2007).

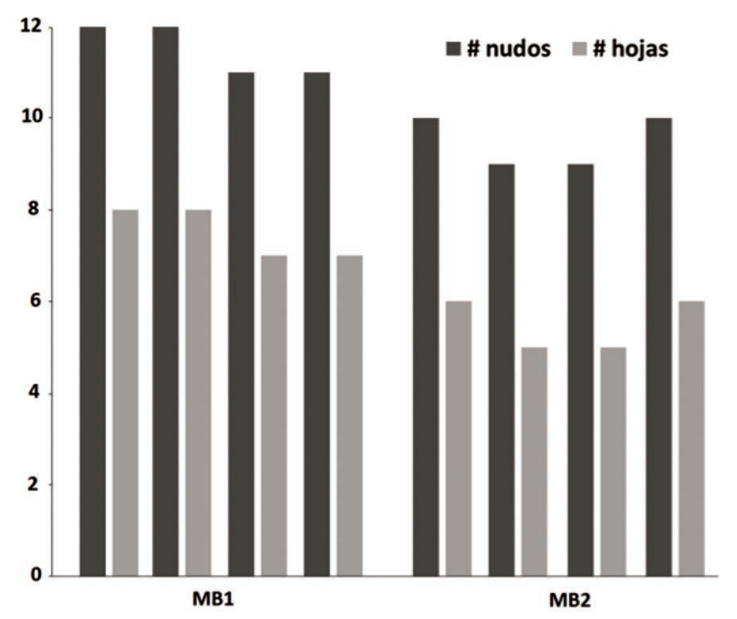

Figura 2. Número de nudos y hojas de yuca (M. esculenta) de acuerdo a los tratamientos MB1 y MB2 con sus respectivas replicas. 
En promedio las plantas que crecen en el sustrato MB1 pueden presentar una altura de $30 \mathrm{~cm}$ hasta los 60 días, mientras que con el MB2 es de $27,5 \mathrm{~cm}$ (Figura 3). Por su parte, el sustrato MB1 presenta al igual que el MB2, una fuente alta de nutrientes, sin embargo, la cascarilla le permite aumentar la porosidad y una mejor disponibilidad de oxígeno y agua necesaria para el desarrollo y endurecimiento (Segovia et al., 2002). En consecuencia, el compuesto MB1 va a permitir un mejor desarrollo radicular, caulinar y foliar que va a facilitar la adaptación ex vitro de las plantas para una posterior etapa de campo.

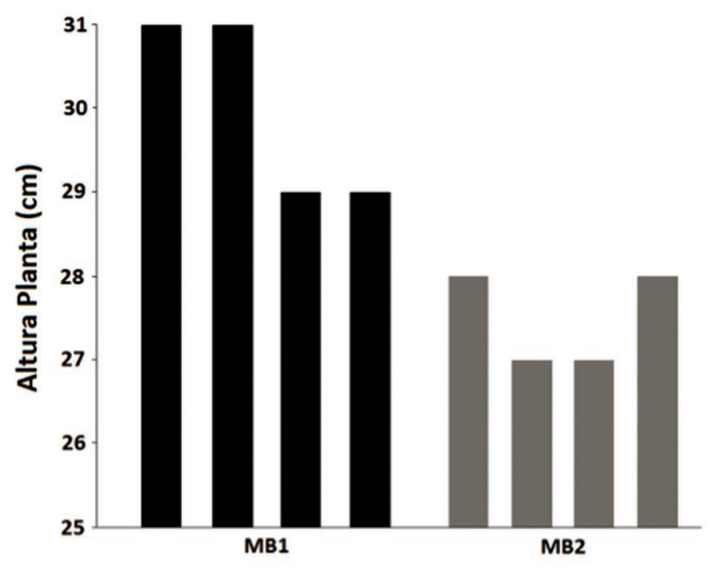

Figura 3. Altura de las plantas de yuca (M. esculenta) versus de acuerdo a los tratamientos MB1 y MB2 con sus respectivas replicas.

El tiempo de endurecimiento fue hasta 60 días, donde las plantas presentaban un idóneo enraizamiento y vigor para salir a fase de campo. En metodología utilizada por Segovia et al. (2002) se define un tiempo de aclimatación de 70 a 90 días, sin embargo, este tiempo incluye que después del endurecimiento, se deja una o dos semanas más por fuera del invernadero, a una exposición completa del sol, por lo que queda disponible para el transplante en campo.

\section{Conclusiones}

Los sustratos orgánicos en conjunto con componentes que permiten la alta porosidad del suelo son una alternativa económica y útil para el manejo de la etapa ex vitro por su fuente nutricional, buen drenaje y adecuada humedad, lo que facilita una mejor aclimatación a las vitroplantas.

El sustrato MB1 es el más idóneo, a nivel nutricional y estructural para el enraizamiento y endurecimiento de plantas de yuca, por lo que se puede considerar como una opción en los procesos de cultivos de tejidos que trabajen con Manihot esculenta.

\section{Agradecimientos}

Los autores expresan sus agradecimientos por el apoyo y financiación por parte de la División de Proyección Social de la Universidad de los Llanos asociada al programa PROGRESO de Acción Social de la República, junto con el Sena sede de Los Naranjos y CORYUMET, para la ejecución del proyecto "Producción de material vegetal de yuca (M. esculenta Krantz) libre de patógenos a través de la propagación in vitro". Adicionalmente a los investigadores María Isabel Moreno, Paul Chavarriaga, Óscar Hernández, Viviana Vargas, Tatiana Zabala, Angela Tovar, Hernán Cortés y Carlos Ariel

\section{Literatura citada}

1. Bonilla, M, Mancipe, C. \& Aguirre, C. (2015). Conservación in vitro: una perspectiva para el manejo de los Recursos Fitogenéticos. Revista de Investigación Agraria y Ambiental. 6 (1): 67-81.

2. Bonilla, M, Pachón, J. \& Moreno, M. (2015). Propagación in vitro de yuca (Manihot esculenta Crantz) variedad brasilera: una alternativa de producción de semilla libre de patógenos para el Meta, Colombia. Cuadernos de Recursos Fitogenéticos Neotropicales. 5-6: 48-60.

3. Bonilla, M, Sánchez, S. \& Pachón, J. (2015). Etapa ex vitro de yuca (Manihot esculenta Crantz) variedad brasilera. Cuadernos de Recursos Fitogenéticos Neotropicales. 5-6: 61-67.

4. Bonilla M, \& Hernández, O. (2012). Propagación in vitro de ñame (Dioscorea spp.): una perspectiva en la producción masiva de plántulas y conservación de germoplasma. Agronomía. 20 (2): 65-76.

5. Carretero, C, Cantos, M, García, J. \& Troncoso, A. (2007). In vitro-ex vitro salt ( $\mathrm{NaCl}$ ) tolerance of cassava (Manihot esculenta Crantz) plants. In Vitro Cellular \& 
Developmental Biology - Plant. 43:364-369.

6. Cortés, S, Chavarriaga, P. \& López, C. (2010). Biocombustibles y biotecnología: la yuca (Manihot esculenta) como modelo de investigación. Acta Biológica Colombiana. 15 (1): 3-24.

7. Escobar, C. (2013). Usos potenciales del humus (abono orgánico lixiviado y solido) en la empresa fertilombriz. (Trabajo de práctica empresarial). Facultad de ciencias administrativas y agropecuarias, Corporación Universitaria la Sallista. 37pp. Recuperado de: http://repository.lasallista.edu.co/dspace/ bitstream/10567/936/1/USOS_POTENCIALES_HUMUS_ABONO_ORGANICO_LIXIVIADO_SOLIDO_ EMPRESA_FERTILOMBRIZ.pdf

8. FAO. (2011). Elaboración y uso de Bocashi. Ministerio de Agricultura y Ganadería, El Salvador. 11 pp. Recuperado de: http://www.fao.org/3/a-at788s.pdf

9. Jorge, M, Robertson, A, Mashingaidze, A. \& Keogh, E. (2001). Distinguishing the effects of light and temperature variations on the growth, development, multiplication potential and ex vitro survival rates of in vitro cassava. Annual of Applied Biology. 138: 363-370.

10. Laynez, J. \& Sánchez, M. (2006). Desinfección de ápices de yuca (Manihot esculenta Crantz) cv. 'Querepa rosada' con hipoclorito de sodio. Revista UDO Agrícola. 6(1):60-66.
11. Marín, A, Albarrán, J, Fuenmayor, F. \& Perdomo, D. (2009). Evaluación del efecto de los reguladores de crecimiento en la regeneración in vitro de cinco cultivares élites de yuca (Manihot esculenta Crantz). Interciencia. 33 (5): 365-371.

12. Murashige, T. \& Skoog, F. (1962). A revised medium for rapid growth and bioassays with tobacco tissue cultures. Physiology Plant. 15:473- 497.

13. Preston, T, Rodríguez, L, Nguyen, V. \& Le, C. (1998). El forraje de la yuca (Manihot esculenta Crrantz) como fuente de proteína para la producción animal en sistemas agroforestales. In: Conferencia Electrónica de la FAO sobre Agroforestería para la Producción Animal em Latinoamérica. Recuperado de: http:// "FAO-Agroforestia-Conferencia \Agroforl.htm"

14. Segovia, R, Bedoya, A, Triviño, W, Ceballos, H, Gálvez, G. \& Ospina, B. (2002). Metodología para el endurecimiento masivo de vitroplantas de yuca. In: Ospina, B, Ceballos, H. 2002. La yuca en el tercer milenio. Sistemas modernos de producción, procesamiento, utilización y comercialización. CIAT. 586 pp.

15. Suárez, L. \& Mederos, V. (2011). Apuntes sobre el cultivo de la yuca (Manihot esculenta Crantz), Tendencias actuales. Cultivos tropicales. 32 (3): 27-35.

16. Souza, E, Guim, A, Batista, A, Zumba, E, Santos, E, Souza, K, Santos, G, Lins, N. \& Matos, D. (2006). Qualidade de silagens de maniçoba (Manihot epruinosa) emurchecida. Archivos de Zootecnia. 55 (212): 351-360.

\section{Conflicto de Intereses}

Los autores declaran no tener ningún conflicto de intereses 